1999-01-01

\title{
Hyperinsulinism Caused by Paternal-Specific Inheritance of a Recessive Mutation in the Sulfonylurea-Receptor Gene
}

\author{
Benjamin Glaser \\ Hebrew University of Jerusalem \\ Fergus Ryan \\ Technological University Dublin, fergus.x.ryan@tudublin.ie \\ Marc Donath \\ Hebrew University of Jerusalem
}

See next page for additional authors

Follow this and additional works at: https://arrow.tudublin.ie/scschbioart

Part of the Biochemistry, Biophysics, and Structural Biology Commons

\section{Recommended Citation}

Glaser, B. et al.:Hyperinsulinism Caused by Paternal-Specific Inheritance of a Recessive Mutation in the Sulfonylurea-Receptor Gene. Diabetes, Vol.48, August 1999. doi:10.2337/diabetes.48.8.1652

This Article is brought to you for free and open access by the School of Biological Sciences at ARROW@TU Dublin. It has been accepted for inclusion in Articles by an authorized administrator of ARROW@TU Dublin. For more information, please contact arrow.admin@tudublin.ie, aisling.coyne@tudublin.ie,gerard.connolly@tudublin.ie.

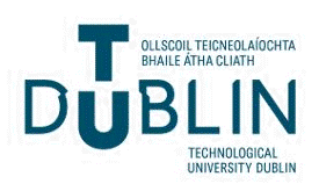




\section{Authors}

Benjamin Glaser, Fergus Ryan, Marc Donath, Heddy Landau, Charles Stanley, Lester Baker, David Barton, and Paul Thornton 


\title{
Antenna \& High Frequency Research Centre
}

\section{Articles}

\section{Hyperinsulinism Caused by Paternal-Specific Inheritance of a Recessive Mutation in the Sulfonylurea-Receptor Gene}

\author{
Benjamin Glaser* \\ Fergus Ryan Dr. ${ }^{\dagger}$ \\ Marc Donath ${ }^{\ddagger}$ \\ Heddy landau** \\ Charles A. Stanley ${ }^{\dagger \dagger}$ \\ Lester Baker ${ }^{\ddagger \ddagger}$
}

David Barton ${ }^{\S} \quad$ Paul S. Thornton

\footnotetext{
*Hebrew University of Jerusalem

${ }^{\dagger}$ Dublin Institute of technology, fergus.x.ryan@dit.ie

${ }^{\ddagger}$ Hebrew University of Jerusalem

**Hebrew University of Jerusalem

${ }^{\dagger \dagger}$ Childrens Hospital of Philadelphia

$\ddagger \ddagger$ Childrens Hospital of Philadelphia

$\S$ National Centre for Medical genetics, Ireland

ฯ The Childrens Hospital, Ireland

This paper is posted at ARROW@DIT.

http://arrow.dit.ie/ahfrcart/1
} 


\section{— Use Licence}

\section{Attribution-NonCommercial-ShareAlike 1.0}

You are free:

- to copy, distribute, display, and perform the work

- to make derivative works

Under the following conditions:

- Attribution.

You must give the original author credit.

- Non-Commercial.

You may not use this work for commercial purposes.

- Share Alike.

If you alter, transform, or build upon this work, you may distribute the resulting work only under a license identical to this one.

For any reuse or distribution, you must make clear to others the license terms of this work. Any of these conditions can be waived if you get permission from the author.

Your fair use and other rights are in no way affected by the above.

This work is licensed under the Creative Commons Attribution-NonCommercialShareAlike License. To view a copy of this license, visit:

- URL (human-readable summary):

http://creativecommons.org/licenses/by-nc-sa/1.0/

- URL (legal code):

http://creativecommons.org/worldwide/uk/translated-license 


\title{
Hyperinsulinism Caused by Paternal-Specific Inheritance of a Recessive Mutation in the Sulfonylurea-Receptor Gene
}

\author{
Benjamin Glaser, Fergus Ryan, Marc Donath, Heddy Landau, Charles A. Stanley, Lester Baker, \\ David E. Barton, and Paul S. Thornton
}

\begin{abstract}
Neonatal hyperinsulinism (HI) is a genetic disorder of pancreatic $\beta$-cells characterized by failure to suppress insulin secretion in the presence of hypoglycemia, resulting in brain damage or death if not adequately treated. Germline mutations in four genes have been associated with HI. Some patients have focal regions of 及-cell proliferation (focal HI). Seventy HI probands in whom at least one $S U R-1$ mutation was identified were studied. Clinical data from patients with two $S U R-1$ mutant alleles were compared with those from patients with single paternally inherited mutations. Thirtyseven probands were homozygous or compound heterozygous for $S U R-1$ mutations. In 33 probands, only a single mutation was identified, and in 31 , the parental origin of the proband could be determined; in 29, the mutation was on the paternal allele $(P<0.0002)$. For three of these, pancreatic tissue was available and showed focal $\beta$-cell hyperplasia. DNA extracted from the focal lesion and adjacent normal pancreas revealed loss of the maternal chromosome $11 \mathrm{p} 15$, resulting in reduction to homozygosity for the $S U R-1$ mutation within the focal lesion only. Using the Tdt-mediated dUTP nick end labeling (TUNEL) reaction, apoptotic $\beta$-cells were identified exclusively within the focal region. At diagnosis, disease severity was similar in patients with paternally inherited mutations and those with two mutations. For patients who did not undergo surgery, those with only paternal mutations entered clinical remission within $16 \pm 6.2$ months, compared with $48 \pm$ 23 months for those with two $S U R-1$ mutations $(P=$ 0.001 ). In conclusion, we identified a novel mechanism to explain the pathophysiology of focal HI and provide evidence to suggest that this entity may be self-limiting, since affected $\beta$-cells undergo apoptosis. Diabetes 48:1652-1657, 1999
\end{abstract}

\footnotetext{
From the Departments of Endocrinology and Metabolism (B.G., M.D.) and Pediatrics (H.L.), the Hebrew University, Hadassah Medical School, Jerusalem, Israel; Our Lady's Hospital for Sick Children (F.R., D.E.B.), Crumlin, and the Children's Hospital (P.S.T.), Dublin, Ireland; and the Division of Endocrinology/Diabetes (C.A.S., L.B.), Department of Pediatrics, Children's Hospital of Philadelphia, Pennsylvania.

Address correspondence and reprint requests to Benjamin Glaser, MD, Division of Endocrinology and Metabolism, Hadassah University Hospital, P.O. Box 12000, Jerusalem, Israel. E-mail: beng@cc.huji.ac.il.

Received for publication 3 December 1998 and accepted in revised form 12 April 1999.

HI, hyperinsulinism; PCR, polymerase chain reaction; SSCP, singlestrand conformational polymorphism; TH, tyrosine hydroxylase; TUNEL, Tdt-mediated dUTP nick end labeling.
}

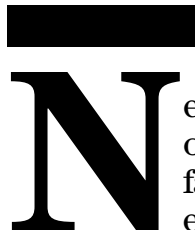
eonatal hyperinsulinism (HI) is a genetic disorder of pancreatic $\beta$-cell function characterized by failure to suppress insulin secretion in the presence of hypoglycemia, resulting in brain damage or death if inadequately treated. Germline mutations in four genes have been associated with HI: the sulfonylurea receptor $(S U R-1)(1)$, an inward rectifying potassium channel (Kir6.2) (2,3), glucokinase $(G K)(4)$, and glutamate dehydrogenase (GLUD-1) (5). Most patients have diffuse involvement of all $\beta$-cells throughout the entire pancreas (diffuse $\mathrm{HI}$ ). A focal form of the disease has been described, however, in which a discrete region of the pancreas contains hyperplastic $\beta$-cells (focal HI), the rest of the pancreas being histologically entirely normal (6). Patients with focal HI have somatic loss of part of the maternal chromosome 11p localized to the hyperplastic region (7). The minimum region lost includes the nonimprinted SUR-1/Kir6.2 genes, the imprinted, maternally expressed tumor suppressor genes $H 19$ and $P 57^{K I P 2}$, and the paternally expressed insulin-like growth factor 2 gene, $I G F-2$. This loss of expressed suppresser alleles may explain the focal $\beta$-cell hyperplasia, but not the severe dysregulation of insulin secretion seen in focal HI. We identified three cases of focal HI with somatic loss of maternal chromosome 11p associated with a mutation in the paternal SUR-1 allele, confirming previous reports $(8,9)$. This combination of events will fully explain the focal HI phenotype and may be responsible for most, if not all, cases of focal HI. Since focal HI cannot be definitively diagnosed without surgical resection, the natural history of the disease can only be studied if a cohort of focal $\mathrm{HI}$ patients who did not undergo surgery can be identified using noninvasive techniques. Genetic analysis can be used to classify HI patients according to risk of having focal HI. Homozygosity or compound heterozygosity for two SUR-1 mutations suggests diffuse $\mathrm{HI}$, whereas heterozygosity for a paternally inherited $S U R-1$ mutation in a $\mathrm{HI}$ patient is consistent with focal HI. We evaluated the mutation status of a cohort of $170 \mathrm{HI}$ probands and identified 37 and 29 patients that fit each of these two criteria, respectively. We then compared the clinical findings in medically treated patients in these two subgroups. Our findings suggest that focal $\mathrm{HI}$ is very severe at diagnosis, but that medically treated patients enter clinical remission much faster than do patients with two mutant SUR-1 alleles $(P=0.001)$. The apparent, self-limiting nature of focal $\mathrm{HI}$ may be explained by an increased frequency of $\beta$-cell apoptosis demonstrated within the focal lesions. 


\section{RESEARCH DESIGN AND METHODS}

Patients. HI was diagnosed using established criteria based on the concomitant finding of hypoglycemia, inappropriately elevated insulin levels, inappropriately low ketone bodies, and abnormally high glucose requirement to prevent hypoglycemia $(10,11)$.

Focal HI patients with histologic evaluation. Three patients with proven focal HI were studied. The first, a non-Jewish Caucasian patient diagnosed with severe hypoglycemia at 42 days of age, was previously reported (8). Due to lack of response to medical treatment, surgery was recommended. A discrete region of adenomatous $\beta$-cell hyperplasia was identified, and a $40 \%$ pancreatectomy was performed. The second case was Ashkenazi Jewish, had severe hypoglycemia immediately after birth, and was large for gestational age (5.36 kg), evidence of intrauterine HI. Having failed to respond adequately to medical management, he underwent surgery at the age of 15 days. Because the focal lesion could not be identified during surgery, a 95\% pancreatectomy was performed. The third patient, a non-Jewish Caucasian, underwent partial pancreatectomy at age 8 weeks. In all cases histologic examination revealed a discrete region of adenomatous hyperplasia, the remainder of the pancreas being normal for age. In all, surgery was curative.

HI cohort. DNA from $170 \mathrm{HI}$ probands and their families was contributed by physicians from North America, Europe, and Israel. Forty-five probands previously underwent comprehensive mutation analysis of all 39 SUR-1 exons using singlestrand conformational polymorphism (SSCP) analysis and direct sequencing. The results of this study were published separately (12). The remaining probands were screened for 24 previously reported SUR-1 mutations $(1,12-15)$ and for novel mutations in the 2nd nucleotide binding domain. Because of the difficulty in obtaining comparable clinical data from all centers, the clinical comparisons reported here were made on a subgroup of 22 patients treated by one of us (H.L.). All ascertainments and treatment decisions were made before the mutation status of any patient was known.

Laboratory methods. DNA was extracted from peripheral lymphocytes using standard methods. Genomic DNA was screened for 24 previously published HI-associated SUR-1 mutations using published materials and methods $(1,12-15)$ and for novel mutations in the 2nd nucleotide binding domain using SSCP as previously described (12).

DNA was isolated from fixed paraffin-embedded pancreatic tissue using standard procedures. Mutations were detected by restriction fragment length polymorphism (RFLP) analysis as previously described (1). To confirm loss of the entire terminal segment of chromosome $11 \mathrm{p}$, two informative polymorphic markers were genotyped in each case. Tyrosine hydroxylase $(\mathrm{TH})$, which is located at the p terminus of chromosome 11, was used for all three cases. One additional informative marker located centromeric to TH was genotyped for each of the three cases (GATA17G04, GATA17G04, and GGAA17G05). Microsatellite analysis was performed using Amplitaq Gold (Perkin-Elmer, Norwalk, CT) for polymerase chain reaction (PCR) and analyzed on a $9 \%$ denaturing long-range gel electrophoresed in a Pharmacia ALF (Uppsala, Sweden) automated sequencing system.

Apoptotic $\beta$-cells were identified by the terminal deoxynucleotidyl transferase-mediated dUTP-X 3' nick end labeling (TUNEL) technique (16). Paraffin sections were deparaffinized, rehydrated, and incubated with $20 \mu \mathrm{g} / \mathrm{ml}$ proteinase $\mathrm{K}$ (Boehringer-Mannheim, Mannheim, Germany) for $15 \mathrm{~min}$ at $37^{\circ} \mathrm{C}$. TUNEL staining was accomplished using the In Situ Cell Death Detection kit (Boehringer-Mannheim) according to the manufacturer's directions. Sections were then incubated for $30 \mathrm{~min}$ at $37^{\circ} \mathrm{C}$ with guinea pig anti-human insulin antibody diluted 1:50 (Dako, Glostrup, Denmark) followed by detection using a streptavidin-biotin-peroxidase complex developed with aminoethylcarbazole (Zymed San Francisco, CA). Finally, sections were counterstained with hematoxylin and embedded in Kaiser's glycerol gelatin (Merck, Darmstadt, Germany). In an effort to obtain an objective estimate of the number of apoptotic $\beta$-cells in the specimens, a strict histologic definition of apoptosis was used. $\beta$-Cells were defined as apoptotic only if anti-insulin antibody-labeled cells exhibited sharply demarcated condensed TUNEL-positive nuclei. Using this definition, it is unlikely that necrotic cells were counted; however, it is possible that cells in different stages of apoptosis were not counted since they did not fit the strict criteria. Trial counts using less strict criteria demonstrated even larger differences between the focal and "normal" regions of the pancreas (data not shown). To estimate the prevalence of apoptotic $\beta$-cells, $100 \beta$-cells were identified in each of 10 random high-powered fields of hyperplastic and normal regions of the pancreas. Only fields with clear, homogeneous staining were included, and fields at the periphery of the section were avoided if any evidence of necrosis or tissue damage was present. The number of definitely positive apoptotic nuclei was counted and hyperplastic and normal regions compared by Fisher's exact test.

Group data are given as means $\pm \mathrm{SD}$, and statistical comparisons were made using Fisher's exact test.

\section{RESULTS}

Focal HI cases. Focal lesions were reported in six patients in whom at least one $S U R-1$ mutation was identified. Three

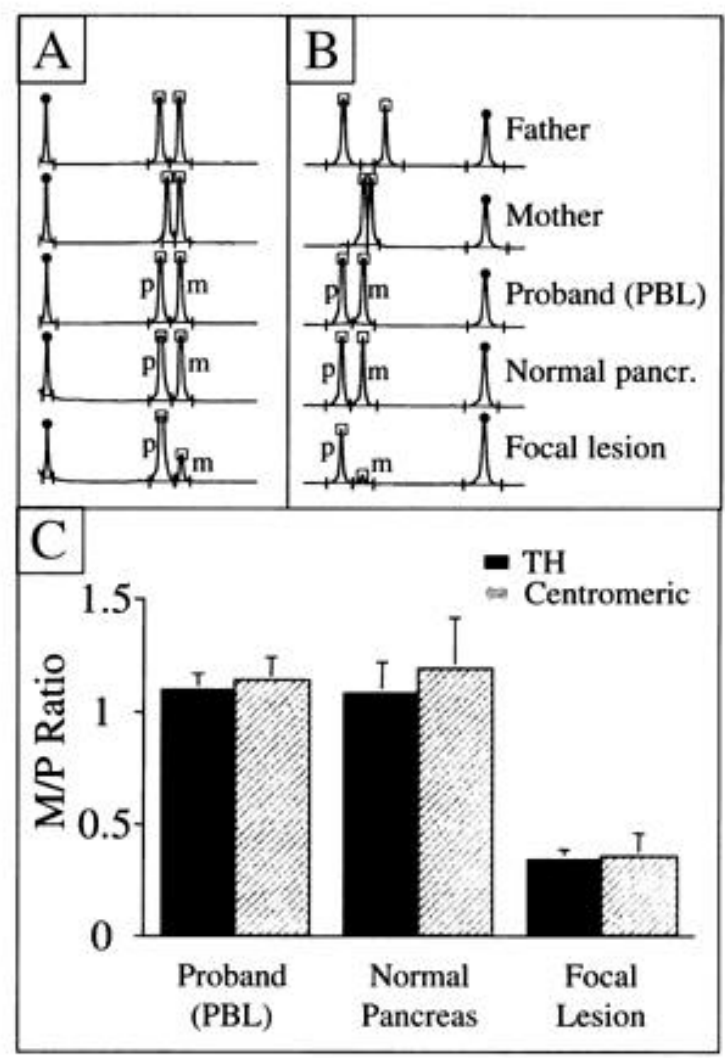

FIG. 1. In all three cases, genotyping was performed on informative polymorphic markers on chromosome 11p as described in METHODS. $A$ and $B$ : Representative ALF traces of $T H$ and GATA17B04 microsatellite analysis for index case 2 . $\square$, PCR products; $\odot$, internal size marker. Genotypes are shown for DNA extracted from peripheral blood lymphocytes (PBL) from the father, the mother, and the proband. Similarly, the DNA extracted from the normal and focal regions of the pancreas was genotyped, and the results are shown. For the proband's PBL and tissue DNA, maternal and paternal alleles are labeled "p" and "m." $C$ : Composite results from all three cases. The relative quantity of maternal and paternal alleles was estimated by calculating the area under the curve for each allele. The maternal/paternal (M/P) ratio is shown. In each case, two informative markers were used, $\mathrm{TH}$, which is near the $p$ terminus of the chromosome, and another informative marker centromeric to TH (see METHODS). The expected ratio of 1 is seen in DNA extracted from peripheral blood and from the "normal" pancreas. In contrast, a low ratio indicative of a marked preponderance of paternal allele is seen in the adenomatous (focal) region.

of these were from the group that underwent mutation screening of all SUR-1 exons, and three were from the group that was screened for both known mutations and for novel mutations in the 2nd SUR-1 nucleotide binding domain. In all six, the proband inherited the $S U R-1$ mutation on the paternal allele of chromosome 11p. Histologic samples were available for confirmation and further study only from the latter three cases, and the further analysis described here was performed only on these three confirmed focal cases. In each, a different mutation was identified, nt1630 $\mathrm{g} \rightarrow \mathrm{t}$, nt3992 $\mathrm{g} \rightarrow \mathrm{a}$, and R1494Q. The first two of these mutations have previously been reported in patients with classical autosomal recessive $\mathrm{HI}$ in whom mutations where identified on both SUR-1 alleles $(12,17)$. DNA extracted from the hyperplastic region of the pancreases contained almost exclusively the mutant allele as demonstrated both by the analysis of informative flanking polymorphic markers (Fig. 1) and by analysis of the mutation itself (Fig. 2). 


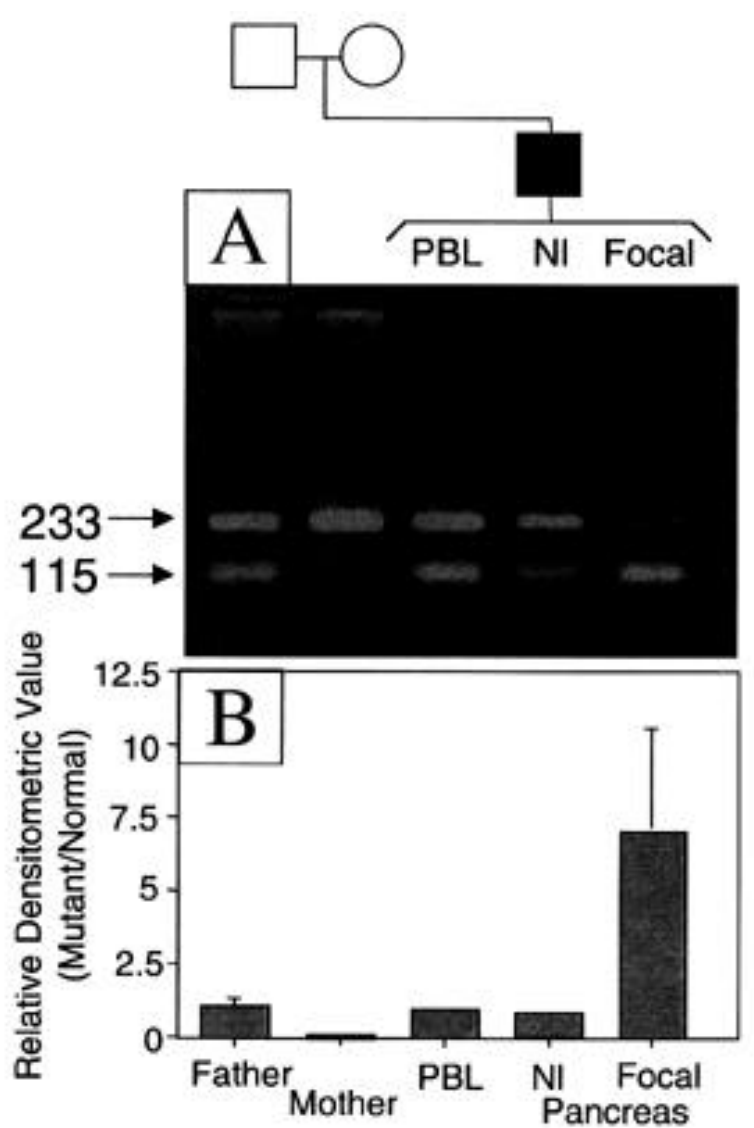

FIG. 2. PCR amplification of DNA followed by restriction-enzyme digestion and ethidium bromide-stained agarose-gel electrophoresis was performed with DNA from all three patients. $A$ : Representative electrophoretic gel demonstrating detection of $\mathrm{R} 1494 \mathrm{Q}$ mutation in index case 3. The first three lanes from the left show genomic DNA extracted from peripheral blood leukocytes (PBL) from the father, mother, and proband. The lanes labeled "Nl" and "Focal" show DNA extracted from fixed, paraffin-embedded normal and focal-lesion pancreatic tissue. When applied to mutant $S U R-1$, the restriction endonuclease Stu 1 digests the 233-bp PCR product to 115- and 118-bp fragments. The wild-type allele is not digested. Genomic DNA from the mother is not digested at all, showing that no mutant allele is present. In contrast, genomic DNA from the father and proband, as well as DNA extracted from the normal pancreas, is partially digested, indicating heterozygosity. In sharp contrast, DNA extracted from the focal lesion was almost completely digested, demonstrating that it contained almost exclusively the mutant allele. $B$ : Histogram showing the ratio of relative densitometric values of similar DNA analysis on all three families. No mutant allele was identified in any of the maternal DNA samples, whereas the ratio of mutant/wild-type allele in genomic DNA from the fathers and the probands as well as DNA extracted from the normal pancreases (NI) showed a mutant/wild-type ratio of $\sim 1$ (range $0.6-1.3$ ). In sharp contrast, DNA from the focal lesion showed a marked preponderance of mutant DNA (ratio $7.0 \pm 3.5, P=0.002$ ).

The surgical specimens were evaluated for evidence of apoptosis (Fig. 3). Seven, three, and five apoptotic cells per $1,000 \beta$-cells were seen in 10 random high-power fields scanned from the focal lesions of the three cases (see METHODS). In contrast, no apoptotic $\beta$-cells were identified in the normal regions of any of the pancreases using identical scanning techniques $(P<0.004)$. Apoptosis was not seen in normal or pathologic tissue obtained from a patient with benign insulinoma (data not shown).

HI patients with $S U R-1$ mutations. One hundred seventy $\mathrm{HI}$ probands were screened for $S U R-1$ mutations as described
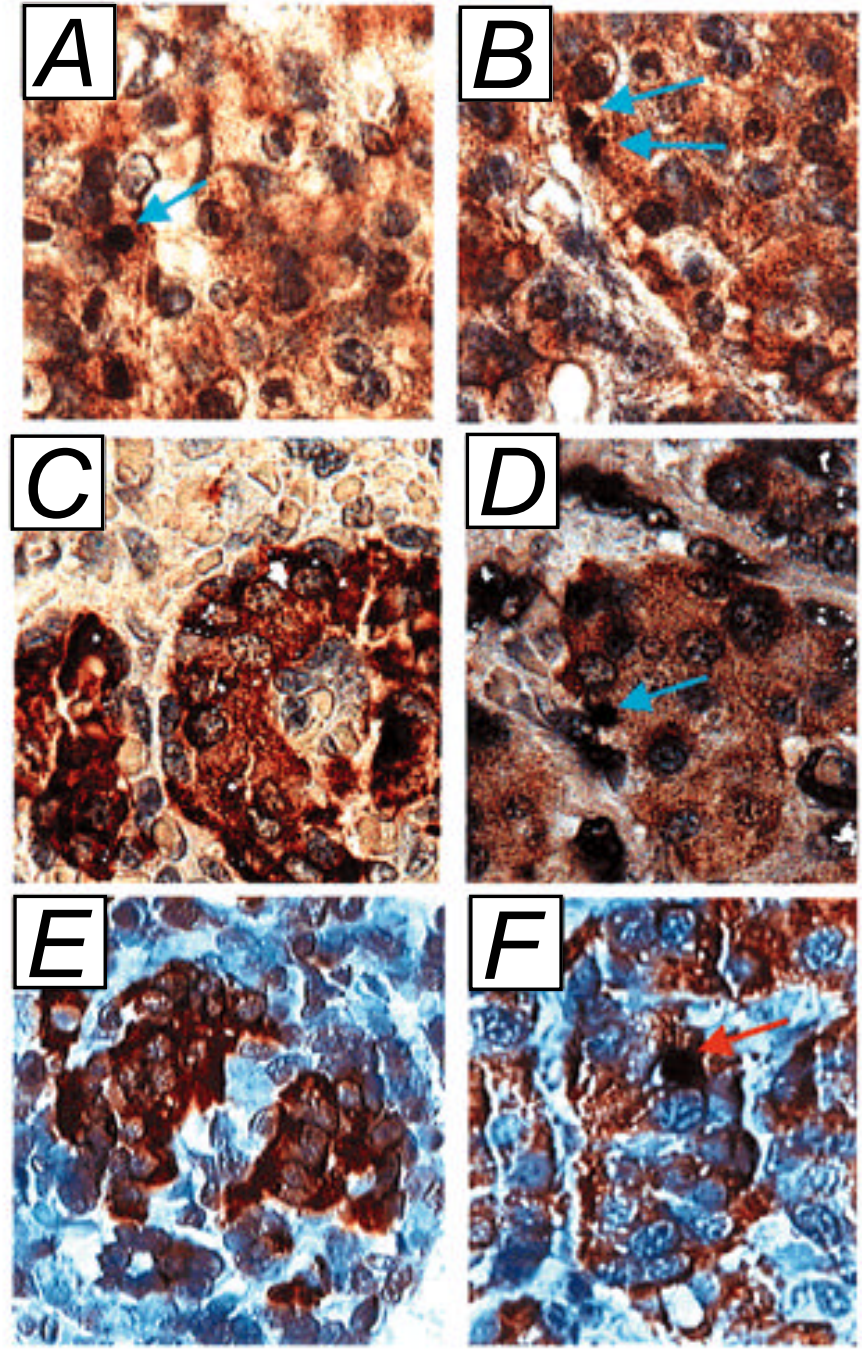

FIG. 3. Photomicrographs of pancreatic tissue double stained for the TUNEL reaction (alkaline phosphatase) and insulin (peroxidase) from all three patients. For patient 1, two examples of the focal lesion are given ( $A$ and $B$ ) since no normal tissue was available for study. For patients $2(C$ and $D)$ and $3(E$ and $F)$, normal tissue $(C$ and $E$ ) is shown alongside the focal lesions ( $D$ and $F$ ). The arrows mark typical apoptotic nuclei.

in METHODS. Thirty-seven probands were found to have two mutant alleles (2MUT), being either homozygotes $(n=23)$ or compound heterozygotes $(n=14)$. In 33 probands, only a single mutation was identified. One of these had a new mutation not found in either parent (12), and for one, DNA was not available from either parent. Therefore, parental origin of the mutation could be determined in 31 probands. In 29, the mutant allele was inherited from the father (1MUT-PAT, $P=0.0002$ ).

To exclude abnormal chromosome segregation in these families, the segregation pattern of the SUR-1 alleles was determined using haplotype analysis in siblings of heterozygous probands with paternal mutations. Nineteen (48\%) of the 40 unaffected siblings carried the paternal mutation, and 8 of these (42\%) also carried the same maternal allele as the affected sibling (Table 1). Only 1 (2.5\%) of 40 siblings had HI, however, and this sibling was haploidentical with the proband at the SUR-1 locus. Thus, although both the maternal and paternal alleles segregated normally, the clinical disease did not $(P=0.004)$. A similar analysis of the families of probands 
TABLE 1

Comparison between probands with two known SUR-1 mutations (2MUT) and those with a single known mutation on the paternal allele (1MUT-PAT)

\begin{tabular}{lccc}
\hline & 2MUT & 1MUT-PAT & $P$ value \\
\hline Number of probands & 37 & 29 & \\
Number of siblings & 94 & 40 & \\
$\quad$ Haploidentical & $25^{*}$ & 8 & 0.51 \\
HI-affected & $23 \dagger$ & $1 \dagger$ & 0.001 \\
Surgery performed & 23 & 12 & \\
$\quad$ Histology report available & 9 & 8 & 0.16 \\
Focal lesions identified & 0 & 6 & 0.002 \\
\hline
\end{tabular}

*Two siblings of one affected individual were found to be homozygous for the $\mathrm{nt} 3992 \mathrm{~g} \rightarrow \mathrm{a}$ mutation. Both were reported to be clinically normal, but neither was examined by a pediatric endocrinologist and neither underwent any specific testing for hypoglycemia. $\dagger$ All affected siblings were haploidentical to the proband at the $S U R-1$ locus.

with two mutant SUR-1 alleles revealed that both allele segregation and affection status segregated normally (Table 1). Furthermore, heterozygous siblings in the two-mutation group were always unaffected regardless of whether the mutant allele was inherited from the mother or the father.

Twenty-three 2MUT and 12 1MUT-PAT patients underwent surgery, but pathology reports are available for only 9 and 8 , respectively. Focal lesions were identified in six of the 1MUT-PAT patients, but in none of the 2MUT group (Table $1, P=0.002$ ).

The genetic and clinical data from the 1MUT-PAT and 2MUT patients were compared. The incidence of specific mutations could only be compared in Ashkenazi Jewish patients since most SUR-1 mutations are rare, usually occurring only in single families (12). In the Ashkenazi Jewish population $>85 \%$ of the HI-associated alleles carry either the nt $3992 \mathrm{~g} \rightarrow \mathrm{a}$ or the delF1388 mutations (14). One of these two mutations was present on $98 \%(n=58)$ of the disease-associated alleles in 2MUT Ashkenazi patients (77\% nt3992 g $\rightarrow$ a; 23\% delF1388) and on $100 \%(n=17)$ of disease-associated chromosomes in 1MUT-PAT patients (76\% nt3992 $\mathrm{g} \rightarrow \mathrm{a}$; 24\% delF1388).

The clinical phenotype and natural history of the disease were also compared. Birth weight was similar in the two groups: $4.04 \pm 0.21$ and $3.81 \pm 0.16 \mathrm{~kg}$ for the $2 \mathrm{MUT}$ and 1MUT-PAT groups, respectively $(P=0.31)$. Other, more subjective clinical data were also compared. However, clinical assessment and treatment approaches differ widely among medical centers, detailed clinical data on many patients referred from abroad was not available, and most centers favor early surgical intervention. Therefore, for the study of the natural history of the disease, we only evaluated patients treated by one of us (H.L.) who, for the last 10 years, has advocated medical treatment whenever possible for all patients, since a substantial percentage of operated patients develop severe diabetes at puberty (18). Thirteen patients with two mutations and nine patients with paternal mutations, none of which underwent pancreatectomy, were evaluated. Both groups had patients with clinically very severe disease ( 7 of 13 and 3 of 9 , respectively, $P=0.41$ ). Age at diagnosis was similar, with 11 of 13 and 6 of 9 patients in each group, respectively, presenting with hypoglycemia within the first $24 \mathrm{~h}$ of life $(P=0.61)$. Interestingly, 8 of the 9 patients with only a sin- gle, paternal mutation entered clinical remission, and drug therapy could be withdrawn after $16 \pm 6.2$ months (range $1-56)$. The ninth patient is still receiving octreotide treatment at the age of 7 months. In contrast, in the group with two mutations, 9 of 13 patients still required drug therapy after 48 \pm 23 months (range 14-88, $P=0.001$ ). The other four became drug independent after 15-107 months. These findings suggest that patients with a single paternal mutation who did not undergo surgery enter clinical remission much earlier than do those with two mutations.

\section{DISCUSSION}

In three patients with focal HI, we demonstrated that somatic loss of maternal chromosome $11 \mathrm{p} 15$ in the focal lesion results in reduction to homozygosity for an inherited SUR-1 mutation and causes severe disease, unresponsive to diazoxide treatment.

deLonlay et al. (7) documented loss of maternal ch11p in 10 patients with focal HI. However, genomic loss of the same region of the maternal chromosome results in BeckwithWeideman syndrome, a syndrome associated with usually mild, transient, diazoxide-responsive hyperinsulinemic hypoglycemia in only about $30 \%$ of cases (19). Since patients with focal $\mathrm{HI}$ have severe $\mathrm{HI}$ unresponsive to diazoxide, loss of maternal chromosome $11 p$ alone is not sufficient to cause the focal HI phenotype. Diazoxide binds to the sulfonylurea receptor causing the $\mathrm{K}_{\mathrm{ATP}}$ channel to increase the mean open time, thereby inhibiting glucose-induced depolarization. Complete loss of $\mathrm{K}_{\mathrm{ATP}}$ function caused by homozygous $S U R-1$ mutations results in severe $\mathrm{HI}$, unresponsive to diazoxide (20). Therefore, reduction to homozygosity of a paternal SUR-1 mutation within the focal lesion fully explains the phenotype seen in focal HI patients. We previously reported one focal HI patient with reduction to homozygosity of the paternal $S U R-1$ mutation in the focal lesion (8), and in a follow-up study of deLonlay's findings, Verkarre et al. (9) reported similar findings in four patients. It is therefore likely that the combination of a paternally inherited $S U R-1$ mutation along with somatic loss of the maternal allele of chromosome $11 p$ is the genetic etiology of most, if not all, cases of focal HI.

It is not possible to study the natural history of focal HI directly, since the definitive diagnosis of a focal lesion can only be made at the time of surgical resection. Furthermore, even in surgically treated patients, the histologic diagnosis of focal $\mathrm{HI}$ is still not accepted in all centers, and therefore unconfirmed histologic reports of diffuse $\mathrm{HI}$ cannot be accepted as definitive evidence. As an alternative approach, we studied 67 HI probands in whom at least one SUR-1 mutation was identified. Patients who inherited mutations on both $S U R-1$ alleles (2MUT) clearly have autosomal recessive disease (AR $\mathrm{HI}$ ). Patients who inherited only a single mutation could also have recessive disease if the second mutation was missed by the screening methods used. Alternatively, they could have disease caused by only a single mutation, such as that found in our three index cases.

We tested the hypothesis that focal HI, because of an inherited paternal SUR-1 mutation and somatic loss of chromosome $11 \mathrm{p}$, is a common cause of HI, and that the natural history of this form of $\mathrm{HI}$ is different from autosomal recessive $\mathrm{HI}$.

In patients with only a single known mutant allele, highly significant preponderance of paternally inherited mutations was found $(P=0.0002)$. The mutation analysis techniques 
used are expected to miss a significant number of mutations, since only a sub-group of patients underwent comprehensive SSCP analysis, and even this technique may miss $10-20 \%$ of mutations. Furthermore, the introns and the regulatory regions of the gene were not screened in any of the patients, and some patients in this heterogeneous cohort may have disease caused by mutations in different genes. These limitations of methodology readily explain the large number of patients (100) in whom no mutation was found. However, no bias was introduced to favor identification of mutant alleles inherited specifically on the paternal allele, as was found in our patients. Only $3 \%(n=1)$ of the siblings of 1MUT-PAT probands were clinically affected, whereas the expected $24 \%$ ( $n=8)$ were haploidentical to the proband. This is not consistent with the hypothesis that mutations are in fact present on the maternal allele in all cases but were missed for technical reasons. Similarly, the alternative hypothesis that the unexpected low incidence of disease in siblings is due to increased mortality or decreased ascertainment efficiency is not supported by these findings. Therefore, our finding that the mutation was on the paternal allele in 29 of 31 probands with a single mutation cannot be explained on the basis of any known methodologic issue.

There is no evidence to suggest that the findings reported here can be explained on the basis of imprinting or allelespecific expression of $S U R-1$ itself. All siblings of 2MUT HI probands who were heterozygous for paternally inherited $S U R-1$ mutations were clinically unaffected.

The clinical characteristics of 2MUT and 1MUT-PAT probands were compared. Onset of disease and clinical severity was similar, consistent with the findings of deLonlay et al. and Verkarre et al. $(7,9)$ for patients with proven focal HI. 1MUT-PAT patients entered clinical remission significantly earlier than 2MUT patients, however. We found an increased number of apoptotic cells in the focal lesions when compared with the rest of the pancreas in all our three patients, suggesting that homozygosity for $S U R-1$ mutations may be associated with increased $\beta$-cell apoptosis. Miki et al. (21) reported a transgenic mouse model that overexpresses a mutant Kir6.2 that disrupts $\mathrm{K}_{\mathrm{ATP}}$ channel activity in a manner analogous to the HI-associated SUR-1 mutations. These mice had hyperinsulinemic hypoglycemia (analogous to human $\mathrm{HI}$ ) in the newborn period, followed by diabetes, associated with $\beta$-cell loss attributed to apoptosis. The same group subsequently reported a Kir6.2 knockout mouse model (22). Interestingly, Kir6. $2^{-/}$mice lack $\beta$-cell $\mathrm{K}_{\mathrm{ATP}}$ channels and have neonatal hypoglycemia and markedly impaired glucosestimulated insulin secretion, but as adults have only mild glucose intolerance. The reason for the difference in clinical expression of the two mouse models is unclear; however, the later phenotype is similar to that seen in some $\mathrm{HI}$ patients after partial pancreatectomy (23). In the Kir6. $2^{-/}$mice, the transient nature of the hypoglycemia may be due to decreased $\beta$-cell mass, and the minimal glucose intolerance may be due to primary or secondary increased sensitivity to insulin, the mechanism of which has yet to be established. Kagimoto et al. (24) demonstrated apoptotic cell death in $\beta$-cells exposed to glibenclamide, a drug of the sulfonylurea class that binds to $S U R-1$, closing the $\mathrm{K}_{\text {ATP }}$ channel. Efanova et al. (25) demonstrated that either hyperglycemia or tolbutamide, a sulfonylurea, can induce apoptosis in $\beta$-cells isolated from $o b / o b$ mice and Wistar rats. Apoptosis could be inhibited by either diazoxide, an antagonist of sulfonylurea effects on $S U R-1$, or D-600, a blocker of L-type calcium channels, suggesting that opening of L-type calcium channels and resultant increased intracellular calcium concentration played an important role in regulating apoptosis. These findings appear to conflict with those of Zhou et al. (26), who demonstrated apoptosis secondary to depletion of intracellular calcium stores, independent of changes in intracellular calcium concentrations. This apparent conflict may be due to the fact that the later study was carried out primarily in the MIN6 cell line and apoptotic signaling in cell lines may be different from that of primary $\beta$-cells in culture. This is suggested by the observation that 10 times higher concentrations of thapsigargin, a drug that depletes intracellular stores, were required in confirmatory experiments on primary cultures of mouse islets.

Recently, $I G F-2$ was shown to protect against apoptosis of $\beta$-cells (27). The $I G F-2$ gene is imprinted, and only the paternal allele is expressed. Expression is high in the fetal and neonatal period and decreases considerably after birth. It is possible that the normally high prenatal $I G F$ - 2 levels explain the prenatal growth of the focal lesion, and the postnatal fall of $I G F-2$ explains the disappearance of the lesion during the first several months of life. A similar increase in apoptosis may also be present in diffuse $\mathrm{HI}$ and may explain the apparent clinical improvement over time seen in these patients. Additional studies are required to confirm these hypotheses.

Our data, when taken together, provide strong evidence to support the hypothesis that as many as $40 \%$ of HI patients may have a single, paternally inherited $S U R-1$ mutation and a second non-Mendelian event (somatic loss of chromosome 11p) causing expression of the recessive disease trait. This series of events fully explains the clinical and genetic data presented here. In the affected clone, all $\mathrm{K}_{\mathrm{ATP}}$ channels are mutated, the maternally expressed tumor suppresser genes are lost, and the paternally expressed growth factor, IGF-2, is expressed. Together, this will result in proliferation of cells unable to turn off insulin secretion in the presence of hypoglycemia. The precise timing of the somatic event will determine the severity and age of onset of clinical disease and the extent of pancreatic involvement. The latter can be limited to a small lesion or to a major portion of the pancreas.

The role of $\mathrm{K}_{\mathrm{ATP}}$ mutations in the genetic susceptibility to type 2 diabetes is still controversial. Several studies have demonstrated associations between common SUR-1 or Kir6.2 polymorphisms and diabetes (28-31). Recently, Goksel et al. (32) reported the association between an apparently silent $S U R-1$ mutation and hyperinsulinemia in nondiabetic subjects. These polymorphisms themselves do not appear to have major effects on the functional characteristics of the channel, and the association may be due to unidentified mutations in the regulatory regions of the genes or in other, closely linked genes.

Our findings of the association between major defects in $\mathrm{K}_{\mathrm{ATP}}$ channel activity and apoptosis suggest that subtle changes in channel function may have major consequences over the life of a patient. Although speculative at this point, these findings may have implications for the pathogenesis and the treatment of type 2 diabetes. Mutations that cause less dramatic changes in channel activity may modulate apoptosis. Furthermore, sulfonylureas, the most common drugs used for treating non-insulin-requiring diabetic patients, cause $\mathrm{K}_{\text {ATP }}$ channels to close in a manner analogous to that seen in $\mathrm{HI}$ 
patients. Our findings, supported by those of others $(24,25)$, raise the possibility that these drugs may be increasing apoptosis of $\beta$-cells, thus hastening the deterioration of $\beta$-cell function characteristic of patients with this disease. Clearly, this requires direct study before any clinical decisions can be made based on this speculation.

\section{ACKNOWLEDGMENTS}

This work was supported in part by National Institutes of Health Grant RR-00240 (C.A.S.), grant 93/00191/2 from the U.S.-Israel Binational Science Foundation (B.G.), and grants 2677 and 4201 from the Israel Ministry of Health (B.G.).

We are grateful to the patients, their families, and physicians for participating in this study. We also gratefully acknowledge the expert technical assistance of Judith Furth.

\section{REFERENCES}

1. Thomas PM, Cote GJ, Wohllk N, Haddad B, Mathew PM, Rabl W, Aguilar-Bryan L, Gagel RF, Byran J: Mutations in the sulfonylurea receptor gene in familial hyperinsulinemic hypoglycemia of infancy. Science 268:426-429, 1995

2. Thomas P, Ye Y, Lightner E: Mutation of the pancreatic islet inward rectifier Kir6.2 also leads to familial persistent hyperinsulinemic hypoglycemia of infancy. Hum Mol Genet 5:1809-1812, 1996

3. Nestorowicz A, Inagaki N, Gonol T, Schoor KP, Wilson BA, Glaser B, Landau H, Stanley CA, Thornton PS, Seino S, Permutt MA: A nonsense mutation in the inward rectifier potassium channel gene, Kir6.2, is associated with familial hyperinsulinism. Diabetes 46:1743-1748, 1997

4. Glaser B, Kesavan P, Heyman M, Davis E, Cuesta A, Buchs A, Stanley CA, Thornton PS, Permutt MA, Matschinsky FM, Herold KC: Familial hyperinsulinism caused by an activating glucokinase mutation. $N$ Engl J Med 338:226-230, 1998

5. Stanley CA, Lieu YK, Hsu BY, Burlina AB, Greenberg CR, Hopwood NJ, Perlman K, Rich BH, Zammarchi E, Poncz M: Hyperinsulinism and hyperammonemia in infants with regulatory mutations of the glutamate dehydrogenase gene. N Engl J Med 338:1352-1357, 1998

6. Rahier J, Falt K, Muntefering H, Becker K, Gepts W, Falkmer S: The basic structural lesion of persistent neonatal hypoglycaemia with hyperinsulinism: deficiency of pancreatic D cells or hyperactivity of B cells? Diabetologia 26:282-289, 1984

7. deLonlay P, Fournet JC, Rahier J, Gross-Morand MS, Poggi-Travert F, Foussier V, Bonnefont JP, Brusset MC, Brunelle F, Robert JJ, Nihoul-Fekete C, Saudubray JM, Junien C: Somatic deletion of the imprinted 11p15 region in sporadic persistent hyperinsulinemic hypoglycemia of infancy is specific of focal adenomatous hyperplasia and endorses partial pancreatectomy. J Clin Invest 100:802-807, 1997

8. Ryan FD, Devaney D, Joyce C, Nestorowicz A, Permutt MA, Glaser B, Barton DE, Thornton PS: Hyperinsulinism: the molecular aetiology of focal disease. Arch Dis Child 79:445-447, 1998

9. Verkarre V, Fournet JC, de Lonlay P, Gross-Morand MS, Devillers M, Rahier J, Brunelle F, Robert JJ, Nihoul-Fekete C, Saudubray JM, Junien C: Paternal mutation of the sulfonylurea receptor (SUR-1) gene and maternal loss of 11 p 15 imprinted genes lead to persistent hyperinsulinism in focal adenomatous hyperplasia. J Clin Invest 102:1286-1291, 1998

10. Aynsley-Green A, Polak JM, Bloom SR, Gough MH, Keeling J, Ashcroft SJ, Turner RC, Baum JD: Nesidioblastosis of the pancreas: definition of the syndrome and the management of the severe neonatal hyperinsulinaemic hypoglycaemia. Arch Dis Child 56:496-508, 1981

11. Landau H, Perlman M, Meyer S, Isacsohn M, Krausz M, Mayan H, Lijovetzky G, Schiller M: Persistent neonatal hypoglycemia due to hyperinsulinism: medical aspects. Pediatrics 70:440-446, 1982

12. Nestorowicz A, Glaser B, Wilson BA, Shyng S-L, Nichols CG, Stanley CA Thornton PS, Permutt MA: Genetic heterogeneity in familial hyperinsulinism. Hum Mol Genet 7:1119-1128, 1998

13. Thomas PM, Wohllk N, Huang E, Kuhnle U, Rabl W, Gagel RF, Cote GJ: Inactivation of the first nucleotide-binding fold of the sulfonylurea receptor, and familial persistent hyperinsulinemic hypoglycemia on infancy. Am J Hum Genet 59:510-518, 1996
14. Nestorowicz A, Stanley CA, Landau H, Glaser B, Permutt MA: Familial hyperinsulinism in Ashkenazi Jews. In Advances in Jewish Genetic Diseases. Desnick RJ, Ed. Oxford, U.K., Oxford University Press. In press

15. Nichols CG, Shyng S-L, Nestorowicz A, Glaser B, Clement JPI, Gonzalez G, Aquilar-Bryan L, Permutt MA, Bryan J: Adenosine diphosphate as an intracellular regulator of insulin secretion. Science 272:1785-1787, 1996

16. Gavrieli Y, Sherman Y, Ben-Sasson SA: Identification of programmed cell death in situ via specific labeling of nuclear DNA fragmentation. J Cell Biol 119:493-501, 1992

17. Nestorowicz A, Wilson BA, Schoor KP, Inoue H, Glaser B, Landau H, Stanley CA, Thornton PS, Clement IV JP, Bryan J, Aguilar-Bryan L, Permutt MA: Mutations in the sulfonylurea receptor gene are associated with familial hyperinsulinism in Ashkenazi Jews. Hum Mol Genet 5:1813-1822, 1996

18. Glaser B, Hirsch HJ, Landau H: Persistent hyperinsulinemic hypoglycemia of infancy: long-term octreotide treatment without pancreatectomy. J Pediatr 123:644-650, 1993

19. Slatter R, Elliott M, Carrera M, Schofield FM, Barton DE, Maher ER: Mosaic uniparental disomy in Beckwith-Wiedemann syndrome. J Med Genet 31: 749-753, 1994

20. Dunne MJ, Kane C, Shepherd RM, Sanchez JA, James RF, Johnson PR, Aynsley-Green A, Lu S, Clement JP, Lindley KJ, Seino S, Aguilar-Bryan L: Familial persistent hyperinsulinemic hypoglycemia of infancy and mutations in the sulfonylurea receptor. N Engl J Med 336:703-706, 1997

21. Miki T, Tashiro F, Iwanaga T, Nagashima K, Yoshitomi H, Aihara H, Nitta Y, Gonoi T, Inagaki N, Miyazaki J-I, Seino S: Abnormalities of pancreatic islets by targeted expression of a dominant-negative $\mathrm{K}_{\mathrm{ATP}}$ channel. Proc Natl Acad Sci US A 94:11969-11973, 1997

22. Miki T, Nagashima K, Tashiro F, Kotake K, Yoshitomi H, Tamamoto A, Gonoi T, Iwanaga T, Miyazaki J, Seino S: Defective insulin secretion and enhanced insulin action in $\mathrm{K}_{\mathrm{ATP}}$ channel-deficient mice. Proc Natl Acad Sci U S A 95: 10402-10406, 1998

23. Leibowitz G, Glaser B, Higazi AA, Salameh M, Cerasi E, Landau H: Hyperinsulinemic hypoglycemia of infancy (nesidioblastosis) in clinical remission: incidence of diabetes mellitus and persistent $\beta$-cell dysfunction at long-term follow-up. J Clin Endocrinol Metab 80:386-392, 1995

24. Kagimoto S, Yamad Y, Kaubota A, Ishida H, Seino Y: Apoptotic cell death of $\beta$-cells triggered by glibenclamide (Abstract). Diabetologia 39:107A, 1996

25. Efanova IB, Zaitsev SV, Zhivotovsky B, Köhler M, Efendic S, Orrenius S, Berggren P-O: Glucose and tolbutamide induce apoptosis in pancreatic $\beta$-cells: a process dependent on intracellular $\mathrm{Ca}^{2+}$ concentration. J Biol Chem 273: 33501-33507, 1998

26. Zhou Y-P, Teng D, Dralyuk F, Ostrega D, Roe MW, Phillipson L, Polonsky KS: Apoptosis in insulin-secreting cells: evidence for the role of intracellular $\mathrm{Ca}^{2+}$ stores and arachidonic acid metabolism. J Clin Invest 101:1623-1632, 1998

27. Petrik J, Arany E, McDonald TJ, Hill DJ: Apoptosis in the pancreatic islet cells of the neonatal rat is associated with a reduced expression of insulin-like growth factor II that may act as a survival factor. Endocrinology 139: 2994-3004, 1998

28. Hani EH, Boutin P, Durand E, Inoue H, Permutt MA, Velho G, Froguel P: Missense mutations in the pancreatic islet beta cell inwardly rectifying $\mathrm{K}^{+}$channel gene (KIR6.2/BIR): a meta-analysis suggests a role in the polygenic basis for type II diabetes mellitus in Caucasians. Diabetologia 41:1511-1515, 1998

29. Hani EH, Clement K, Velho G, Vionnet N, Hager J, Philippi A, Dina C, Inoue H, Permutt MA, Basdevant A, North M, Demenais F, Guy-Grand B, Froguel P: Genetic studies of the sulfonylurea receptor gene locus in NIDDM and in morbid obesity among French Caucasians. Diabetes 46:688-694, 1997

30. Inoue H, Ferrer J, Welling CM, Elbein SC, Hoffman M, Mayorga R, Warren-Perry M, Zhang Y, Millns H, Turner R, Province M, Bryan J, Permutt MA, AquilarBryan L: Sequence variants in the sulfonylurea receptor (SUR) gene are associated with NIDDM in Caucasians. Diabetes 45:825-831, 1996

31. Hansen T, Echwald SM, Hansen L, Moller AM, Almind K, Clausen JO, Urhammer SA, Inoue H, Ferrer J, Bryan J, Aguilar-Bryan L, Permutt MA, Pedersen O: Decreased tolbutamide-stimulated insulin secretion in healthy subjects with sequence variants in the high-affinity sulfonylurea receptor gene. Diabetes 47:598-605, 1998

32. Goksel DL, Fischbach K, Duggirala R, Mitchell BD, Aguilar-Bryan L, Blangero J, Stern MP, O'Connell P: Variant in sulfonylurea receptor-1 gene is associated with high insulin concentrations in non-diabetic Mexican Americans: SUR-1 gene variant and hyperinsulinemia. Hum Genet 103:280-285, 1998 